EXEMPLARIa Classica

Journal of Classical Philology

19, 2015, pp. $155-173$

ISSN 1699-3225

\title{
UNA LECTURA CONJUNTA DEL PRIMER ENCOMIO $A$ CONSTANCIO Y EL ENCOMIO A EUSEBIA DE JULIANO*
}

Ma PILAR García RUIZ

Universidad de Navarra

mpgarcia@unav.es

SUMMARY

This contribution analyses Julian's First

Panegyric in honour of Constantius and the Panegyric in Honour of Eusebia as complementary texts. The presence of a shared reference to the eulogy based on virtues; a particular meaning of

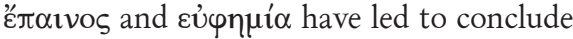
that, these speeches constituted a double

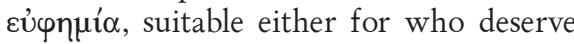
it or not. Mordant commentaries on Constantius in both panegyrics and some other structural arguments support the thesis that the speeches would have been rewritten subsequently.

KEYWORDS

Panegyrics, Emperor Julian (331-363), First Panegyric in honour of Constantius, Panegyric in Honour of Eusebia.
Resumen

En este artículo se estudia conjuntamente el primer Encomio a Constancio y el Encomio a Eusebia del César Juliano con vistas a corroborar o descartar la hipótesis de que existan lazos de estructura y contenido comunes a ambos discursos. La referencia compartida al elogio basado en virtudes,

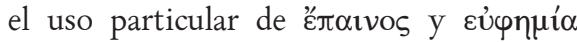
apuntan a que fueron concebidas como una

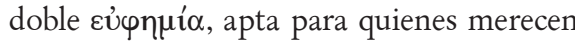
y no merecen un elogio, según las categorías de Juliano. Los comentarios mordaces contra Constancio presentes en los textos conservados junto con otros argumentos de tipo estructural avalan la tesis de la reescritura de ambos discursos.

Palabras Clave

Panegíricos, emperador Juliano (331-363), primer Encomio a Constancio, Encomio a Eusebia.

Fecha de recepción: 19/05/2015

Fecha de aceptación y versión final: 06/08/2015

* Este trabajo es resultado del Proyecto de investigación 'Alteridad lingüística y cultural en el Imperio Romano (ss.III-IV): historiografía y géneros afines' (MINECO FFI2010-15402). Una primera versión del mismo fue presentada en la XVIII Bienal de la ISHR (Bologna, 2012) con el título "Lectura y exégesis conjunta de las orationes 1 y 2 del emperador Juliano". Deseo expresar mi agradecimiento a los profesores José B. Torres y Álvaro Sánchez-Ostiz y muy especialmente a los revisores del artículo por sus comentarios y sugerencias. 
1. El PRimer ENCOMio a CONSTANCIO y el ENCOMIO a EUSEBIA: CiRCUNSTANCIAS DE COMPOSICIÓN

En los últimos años las primeras manifestaciones de la producción literaria de Juliano, sus tres primeras orationes ${ }^{1}$, primeras pero no rudimentarias en cuanto a la pericia técnica en el género del que son expresión, están encontrando su lugar como piezas de valor no poco importante a fin de restaurar el complejo mosaico de la personalidad de su autor ${ }^{2}$.

Entre ellas, el primer Encomio a Constancio y el Encomio a Eusebia, esposa de Constancio parecen proceder de momentos y circunstancias cercanos $^{3}$. Las noticias de carácter cronológico ${ }^{4}$ contenidas en ambos textos apuntan a que su autor los escribió siendo César de la Galia, muy probablemente entre el otoño del 356 y la primavera del $357^{5}$.

${ }^{1}$ Sigo a J. Bidez, L'empereur Julien. Ouvres complètes, I-1 ${ }^{r e}$ (Discours de Julien César), Paris 1932, I.1, xxx-xxxii, que propuso la reordenación de los escritos según un criterio cronológico: Primer Encomio a Constancio = oratio 1; Encomio a Eusebia = oratio 2 (anteriormente oratio 3); Sobre las acciones del emperador o Sobre la realeza, pasa a ser la oratio 3. Por el contrario Wright, Works, conserva el orden de los manuscritos. Para el texto griego he utilizado la edición crítica de Bidez, para la traducción la de García Blanco sobre la que en ocasiones he hecho enmiendas.

2 A. Pagliara, "Giuliano Cesare panegirista di Costanzo II", en A. Marcote, ed., L'imperatore Giuliano. Realtà storica e rappresentazione, Firenze 2015, 109.

${ }^{3}$ E. van Borries, "Iulianus", $R E$ 10.1.1918, coll. 34 y 68; J. Bidez, La vie de l'empereur Julien, Paris 1965 (repr. 1930), 379 n. 7; L'empereur Julien, 3; P. Athanassiadi, Julian. An intellectual biography, London 1992 (repr. 1981), 74; W. Portmann, Geschichte in der spätantiken Panegyrik, Frankfurt 1988, 138, 262; S. Angiolani, Elogio dell'imperatrice Eusebia (Orazione II), Napoli 2008, 17-18; E. Redondo Moyano, "Encomio de personajes femeninos: Elogio de la emperatriz Eusebia de Juliano el Apóstata”, en M T. Muñoz García de Iturrospe, ed., Antiguos y Modernos. Presencias clásicas, de la Antigüedad al siglo

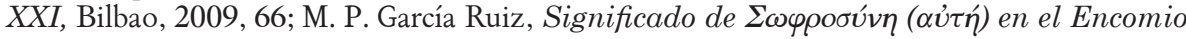
a Eusebia de Juliano, Emerita 80, 1, 2012, 71.

${ }^{4}$ Del periodo 355-360 contamos sólo con fuentes favorables a Juliano y con los escritos del propio interesado, especialmente el relato exculpatorio de la Epístola a los atenienses (Or. $5.277 \mathrm{~d}-278 \mathrm{~b}$ ). La naturaleza tendenciosa de este relato sobre sus experiencias en la Galia es evidente incluso sin consultar otras fuentes (G. W. Bowersock, Julian the Apostate, Cambridge Mass. 1997, 34; D. Hunt, “Julian”, en A. Cameron \& P. Garnsey, eds., The Cambridge Ancient History, Cambridge, Vol. XIII, 1998, 49; S. Tougher, Julian the Apostate. Debates and Documents in Ancient History series. Edinburgh 2007, 31-32).

${ }^{5}$ En el Encomio a Constancio se menciona la campaña del verano de 356 (Jul. Or. 1, 45ab; cf. Or. 5.277d-278d; Amm. Marc. 16.2-4), pero no hay referencias a la campaña del verano del 357 en la que Juliano llegó a cosechar triunfos importantes como la Batalla de Estrasburgo (Jul. Or. 5.278d; cf. Lib. Or. 18.48; Amm. Marc. 16.12). Por lo que respecta al Encomio a Eusebia, también se alude a la campaña del 356 (Jul. Or. 2.124b y d) y al viaje que la emperatriz Eusebia realizó a Roma ese mismo año (Jul. Or. 2.129bc), si bien no nombra la estancia de Constancio en Roma prevista en la primavera del 357 (Amm. Marc. 16.10.18). Todo ello permite situar los discursos en el arco temporal del invierno del 356-357, vid. I. Tantillo, La prima orazione di Giuliano a Costanzo, introduzione, traduzione e commento, Roma 1997, 36-40; Angiolani, Elogio dell'imperatrice, 17-20 y bibliografía contemporánea sobre la cuestión; para las opiniones de los comentaristas anteriores al siglo XX, vid. Pagliara, Giuliano Cesare, 90-91. 
Parece probable que Juliano ideara el Encomio a Eusebia como complemento al Primer Encomio a Constancio, siguiendo las pautas de los manuales de retórica. El tratadista Menandro proponía dedicar un apartado a la esposa del emperador, si las cualidades de esta así lo merecían (Men. Rh. 2.376.9-13), y la ausencia de referencias a la emperatriz Eusebia en el Encomio dirigido al emperador hace pensar que la oratio 2 cumplía esa misión 6 .

Este primer Encomio a Constancio, un panegírico que glosa las principales virtudes y hazañas del emperador, se suele interpretar como un gesto diplomático de Juliano, deseoso de honrar al emperador y manifestarle su lealtad en sus primeros tiempos como César ${ }^{7}$. El propósito del Panegírico a Eusebia se haya explícito en el texto: Juliano afirma que satisfacía con él una deuda de gratitud por los beneficios recibidos ${ }^{8}$. Gracias a la intervención de la emperatriz, Juliano fue absuelto de la acusación de haberse reunido con su hermano Galo para conspirar contra Constancio y obtuvo permiso para proseguir sus estudios en Atenas; también por mediación de Eusebia, en noviembre del 355, fue nombrado César para la Galia, se acordó su matrimonio con Helena, hermana de Constancio, y, por último y no menos importante para el joven filósofo, Eusebia le regaló una biblioteca bien dotada que le acompañó a la Galia ${ }^{9}$. Aun teniendo en cuenta el género laudatorio al que pertenecen, una parte significativa de la crítica coincide en destacar que el Elogio de Eusebia transmite sinceridad, mientras que el de Constancio sigue de tal forma las pautas marcadas por la escuela que resulta excesivamente reiterativo y formal ${ }^{10}$.

Apoyándose en el relato de Amiano Marcelino, Bidez defendía que estos discursos habían sido enviados a Constancio por medio del chambelán Euterio a principios del 357. Aquel invierno el magister equitum Marcelo había desatendido a Juliano en el asedio de Sens y posteriormente marchó a Milán donde acusó a Juliano ante el consistorio de "ser un ambicioso y de prepararse unas alas más fuertes para volar más alto". La necesidad de defenderse frente a las acusaciones de Marcelo habría impulsado a Juliano

${ }^{6}$ Bidez, L'empereur Julien, I.1, 71; N. Aujoulat, “Eusébie, Hélène et Julián (I)”, Byzantion 53, 1983, 78; Tantillo, Prima orazione, 39-40, n.135; S. Tougher, In Praise of an Empress: Julian's Speech of Thanks to Eusebia, en M. Whitby (ed.), The Propaganda of Power. The Role of Panegyric in Late Antiquity, Leiden-Boston-Köln, 1998, 109; Angiolani, Elogio dell'imperatrice, 6-7; Redondo Moyano, "Encomio", 66, 78, 79 n.5.

${ }^{7}$ Tougher, In praise, 107; id. Julian, 38-39; Bowersock, Julian, 37.

${ }^{8}$ Sobre la benévola imagen de la emperatriz que transmite Juliano en este panegírico y su contraste con la de Amiano en las Res Gestae, vid. M. P. García Ruiz, "Eusebia vista por Amiano: un retrato entre líneas", $C F C(L)$ 28.2, 2008, 49-64 y bibliografía citada.

${ }^{9}$ El relato de los beneficios recibidos se halla en Or. $2.117 \mathrm{~d}-118 \mathrm{~d}$, las referencias a la gratitud a lo largo de todo el discurso.

${ }_{10} \mathrm{~W}$. C. Wright, The works of the emperor Julian, 3 vols., Cambridge Mss.-London 1913-1923, 273; Bidez, L'empereur Julien, I.1, 9; Athanassiadi, Julian, 61; Angiolani, Elogio dell'imperatrice, 30. 
a enviar al eunuco Euterio ante el consistorio de Milán (Amm. Marc. 16.4; 7.1-3). Aunque resulta sugerente, no es posible afirmar con seguridad que los Encomios contribuyeran al acercamiento entre el Augusto y su primo, puesto que no hay en ellos referencia a los sucesos ${ }^{11}$. Ciertamente, el relevo de Marcelo por Severo, un general más afín a los gustos de Juliano (Amm. Marc. 16.11.1) $)^{12}$ y la invitación a que Helena, hermana de Constancio y esposa de Juliano, participara en los fastos por la celebración del triunfo del emperador en Roma (Amm. Marc. 16.10.18), indican que Constancio no sólo desoyó las acusaciones del general sino que, a partir de entonces, reforzó sus lazos de confianza con Juliano ${ }^{13}$.

En cualquier caso, quienes han estudiado estos discursos los consideran estrechamente vinculados ${ }^{14}$. Bidez veía en ellos "una misma disposición, un mismo espíritu, unas mismas preocupaciones y declaraciones del autor" Más recientemente Redondo Moyano sintetizaba con acierto: "el discurso de elogio del emperador iba acompañado del dirigido a Eusebia; ambos formaban una unidad y fueron diseñados por Juliano como dos partes de un conjunto que tenía una misma finalidad"16.

Por mi parte, me he propuesto analizarlo conjuntamente con vistas a determinar qué lazos de estructura y/o contenido existen entre ellos. En este artículo he abordado, en primer lugar, las temáticas comunes, lo cual me ha llevado a advertir el uso particular que Juliano hace de los términos que designan 'elogio', en función del elogio filosófico que pretende; a continuación me he ocupado de la estructura de los discursos, dedicando una sección a se a los epílogos. Los resultados alcanzados me llevan a sostener que los dos discursos

${ }^{11}$ Únicamente indicios como pongo de manifiesto en M. P. García Ruiz, "The 'Marcellus case' and the loyalty of Julian: latent arguments and Otherness in Ammianus' Res Gestae", Talanta 45, 2013, 81-96. Allí también analizo el relato de Amiano sobre la campaña anterior, la actitud de Marcelo y la comparecencia de Milán.

${ }^{12}$ Por mediación de Eusebia, según Zósimo 3.2.2.

${ }^{13}$ Aunque no como Juliano explica en su Epistola a los atenienses, en la que da una versión manipulada de los hechos sosteniendo que Constancio le confió el mando de las tropas en la primavera del 357, Jul. Or. 5.278d: "después de lo cual, Constancio que pensaba que habían mejorado un poco pero no imaginaba que los asuntos de la Galia hubieran experimentado un cambio tan grande, me entrega el mando del ejército al comienzo de la primavera"; siguen esta versión Lib. Or. 18.48 y Zos. 3.2.2. Amiano afirma claramente en 16-12, 14; 20.8.14 que durante el tiempo que Juliano fue César el emperador siguió designando a los altos funcionarios imperiales civiles y militares también en la Galia, vid. García Ruiz, "Marcellus case”, 83-88.

${ }^{14}$ Muchos de los estudios particulares dedicados a uno $\mathrm{u}$ otro discurso coinciden en esta opinión: Tantillo, Prima orazione, Tougher, Reading; y para el Encomio a Eusebia vid. Tougher, In praise; Angiolani, Elogio dell'imperatrice, L. James, "Is there an empress in the text? Julian's Speech of Thanks to Eusebia", en N. Baker-Brian and S. Tougher, eds., Emperor and author. The writings of Julian the Apostate, Swansea 2012, 47-59; K.Vatsend, Die rede Julians auf Kaiserin Eusebia. Abfassungszeit, Gattungszugehörigkeit, panegyrische

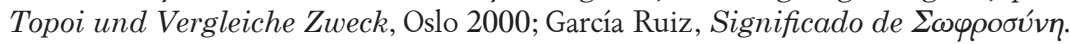

${ }^{15}$ Bidez, L'empereur Julien, I.1, 71.

${ }^{16}$ Redondo Moyano, "Encomio”, 66. 


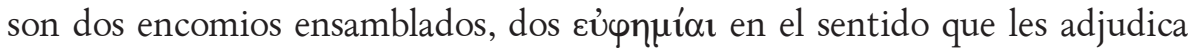
Juliano. La presencia en ambos discursos de pasajes críticos hacia la persona del emperador y algunas ausencias en el ámbito de la estructura parecen reforzar la teoría de que las orationes fueron reescritas con posterioridad.

\section{TÓPICA Y TÉRMINOS COMUNES}

Una lectura detenida de los discursos pone de manifiesto que los exordios de ambas orationes y el epílogo de la oratio 2 comparten un mismo hilo conductor. En los exordios Juliano se plantea un dilema, practicar el elogio filosófico que exalta las virtudes o el elogio del arte guiado por el deseo de agradar y con él el problema de la adulación, dilema que retoma en el epílogo del discurso a Eusebia ${ }^{17}$.

Al comienzo del Encomio a Constancio, Juliano se califica a sí mismo como inexperto en cuestiones oratorias y se sitúa entre quienes practican el elogio filosófico frente a los rétores y los aduladores de la riqueza y del poder. Estos oradores expertos en el arte oratorio son capaces de disertar de manera elevada acerca de asuntos pequeños (Jul. Or. 1.2c), en cambio quienes buscan la filosofía y la virtud se valen de otras formas de hablar encaminadas hacia lo mejor (Jul. Or. 1.4b). La doctrina del elogio filosófico, es decir, del elogio de las virtudes, se remonta a Aristóteles (Arist. Rhet.1.1367b, 27-33; cf. EN1101b, 31-34); si bien Juliano tuvo un modelo más cercano en el orador Temistio, cuyos discursos conoció y acomodó en líneas generales ${ }^{18}$.

En el exordio del Encomio a Eusebia Juliano pone el acento en el peligro de la ingratitud y se lamenta de aquellos que se retraen del elogio por miedo a caer en la adulación. Él es partidario de alabar las bellas acciones, si estas honran la verdad ${ }^{19}$. En el epílogo Juliano defiende que, practicando el elogio de las virtudes, ha relatado la verdad, aunque muchos juzguen los hechos escogidos como aparentemente sin importancia y le consideren un hombre simple e ignorante en el arte de la palabra ${ }^{20}$. Ciertamente esta es una falsa modestia. Como demuestran estos y otros discursos, Juliano tuvo una excelente formación retórica y sabía, como se verá, servirse de los conocimientos retóricos en su propio provecho ${ }^{21}$.

${ }^{17}$ Elogio filosófico versus retórico y el peligro de adulación: Or. 1.1-4c; Or. 2.102a-104b; 126b-128b, esp. 126c.

${ }^{18}$ Sobre las líneas generales del elogio filosófico, vid. la exposición del propio Temistio en su Or. 1.1a-3a. Bajo esta perspectiva escribió las orationes 1-4 dedicadas a Constancio. Los críticos discuten si entre Juliano y Temistio cabe hablar de dependencia o de modelos comunes; Tougher, Reading, 22-24 ofrece un resumen de las principales posiciones en este asunto.

${ }_{19}$ Jul. Or. $2.102 \mathrm{~d}-103 \mathrm{~b}$.

${ }^{20}$ Jul. Or. 2.126bd; 128b: "muchos, convencidos por los bienaventurados sofistas, dirán que tomando asuntos sin duda pequeños e insignificantes, os los presento como si fueran algo magnífico (...) No sé por qué, los que de todo pretenden hacer grandes discursos se enojan contra los que no tienen su misma inclinación y los acusan de rebajar la fuerza de los discursos".

${ }^{21}$ L. Pernot, La rhétorique de l'éloge dans le monde greco-romain, 2 vol., Paris 1993, 493- 


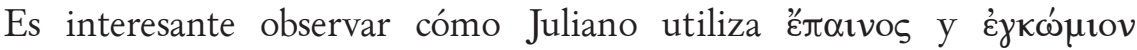
siguiendo las pautas del elogio filosófico: éđaıvos 'elogio de la virtud' y

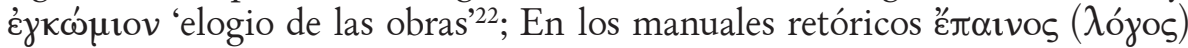
designaba 'elogio' en sentido amplio y ézкć́ el discurso del género demostrativo, si bien la tendencia entre los tratadistas y oradores era considerarlos como términos sinónimos ${ }^{23}$.

En este contexto, resulta muy significativo que Juliano nunca designe

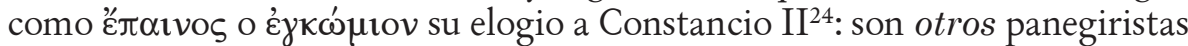

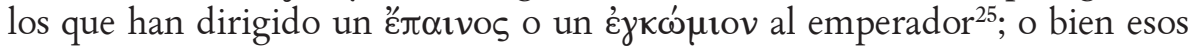
términos se encuentran en frases interrogativas ${ }^{26}$, negativas o genéricas, como si quisiera evitar calificar su discurso al emperador en esos términos ${ }^{27}$. Por el contrario, Juliano sí afirma que desea realizar un Ěđaıvos para Eusebia en

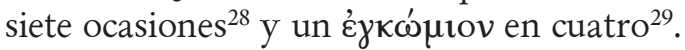

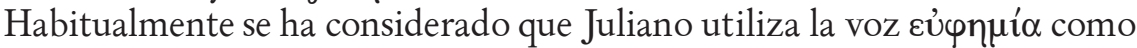
sinónimo de las voces anteriores. En general eủ prudente de juicios cuya expresión directa sería dura o malsonante" y se utiliza con ese significado en el ámbito específico de la alabanza ${ }^{30}$. Este término se

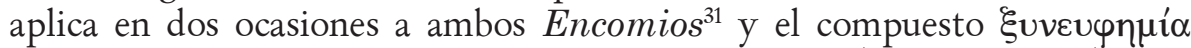
'alabanza paralela' en una referido al elogio de Eusebia (Jul. Or. 2.106c).

Hechas estas precisiones terminológicas, quiero llamar la atención sobre algunas afirmaciones preliminares en las que se contienen estos términos. En el prólogo a la oratio a Constancio Juliano defiende que el ह̌ $\pi \alpha \imath v o \varsigma$ verdadero sólo le corresponde en propiedad al que posee la virtud (Jul. Or. 1.5b):

605, comenta por extenso las relaciones entre la filosofía y la retórica en el marco del discurso epidíctico. Particularmente interesantes son las páginas dedicadas a "L'enkomion concilié avec la philosophie", 591-605, en las que expone cómo los oradores 'filosofos' han reivindicado esta doctrina y practicado este tópico en sus elogios.

${ }^{22}$ Arist. Rhet. I 1367b, 27-33; cf. EN 1101b, 31-34.

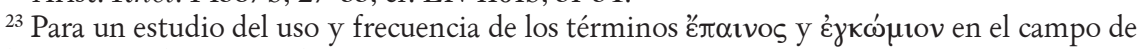
los discursos epidícticos, vid. Pernot, La Rhetorique, 117-128.

${ }^{24}$ Excepto en el título de la obra que probablemente no sea de Juliano.

${ }^{25}$ Jul. Or. 1.1; 3a.

${ }^{26}$ Jul. Or. $1.4 \mathrm{c} ; 19 \mathrm{c}$.

27 Jul. Or. 1.2b, 10a, 19c, 47a.

28 Jul. Or. 2.106a, 112d, 115d, 115d (bis), 116b, 128d, 129b.

${ }^{29}$ Jul. Or. 2.104b, 110a, 114b, 116b.

30 TLG s. v. dicitur is modus laudandi quo in optimam partem interpretamur, si qua ab aliquo peccata recensenda sint. Con el significado de 'panegírico' TLG sólo cita Jul. Or.1.4b, y Liddell-Scott s. v. III, 2 Jul. Or. 2.106a y Lib. Or. 62.3. El término podría tener también connotaciones religiosas, en paralelo con la expresión latina fauere linguis, pero no en este contexto.

${ }^{31}$ Se encuentra dos veces en la oratio 1, Jul. Or. 1.4c, 5a; y siete en la oratio 2, de las cuales sólo dos se refieren al elogio de Eusebia, Jul. Or. 2.103b y 104b; las otras, 103c, 104c, 105c, 125a

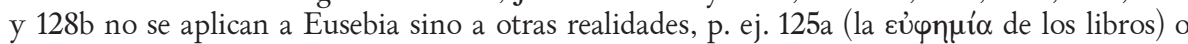
pertenecen a enunciados de tipo general. 
las obras de la virtud son sólo del que las hace y el elogio que de ellas procede, al ser

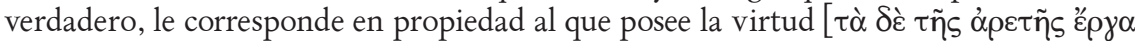

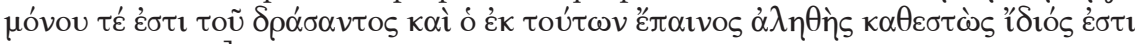

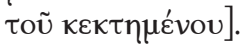

Si bien los 'oradores del arte' no consideran vergonzoso elogiar en falso,

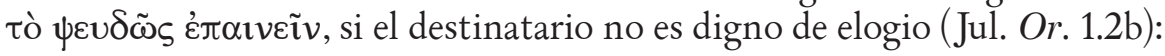

[a los oradores su arte les proporciona una libertad equivalente a la de los poetas y] este [arte] no prohíbe en absoluto la adulación y no reconoce que sea vergonzoso

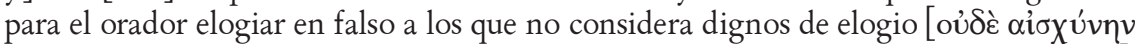

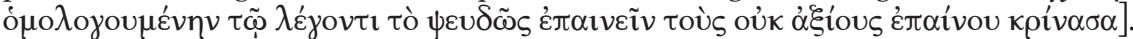

En el prólogo a la oratio a Eusebia sostiene que la \&ủ $\varphi \eta \mu i ́ \alpha$ es recomendable tanto para quienes la merecen, como para quienes no la merecen (Jul. Or. 2.103c):

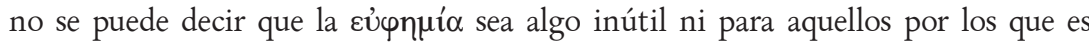
pronunciada ni para aquellos otros, que pese a haber obtenido el mismo puesto en la vida, estuvieron lejos de la virtud en sus acciones. Pues para los primeros es algo agradable de escuchar y que les predispone a obras hermosas y superiores, y a los otros los estimula con aquella persuasión e ímpetu a la emulación, viendo que ninguno de sus predecesores ha sido privado de lo que únicamente es hermoso dar y recibir en público.

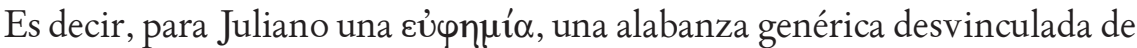
la virtud, resulta beneficiosa tanto para quienes la merecen como para quienes no la merecen, porque todos sacan provecho: a los virtuosos les predispone a otras hermosas acciones, a los otros les estimula a la emulación.

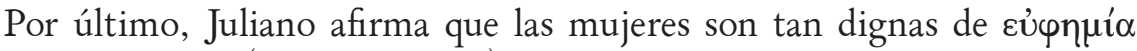
como los hombres (Jul. Or. 2.104b):

me parecería extraño que, elogiáramos gustosos a los hombres, y, en cambio, no

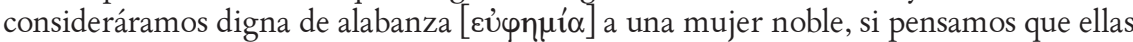
son capaces de una virtud en nada inferior a la de los hombres ${ }^{32}$.

Así pues, en los prolegómenos de los discursos Juliano parece establecer una serie de principios sobre la práctica del elogio basado en virtudes que podrían resumirse así: existe un ह̌ $\pi \alpha$ ivo verdadero que se apoya en las virtudes y un

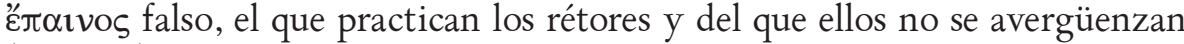

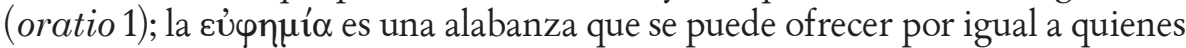
la merecen y a quienes no son dignos de ella, un género de encomio que se puede practicar sin faltar a los principios del elogio filosófico, apto tanto para hombres como para mujeres (oratio 2). He investigado en qué medida esas pautas tienen su reflejo en los textos.

${ }^{32}$ Cf. 104 c y 105 c. 


\section{3. ¿UNA ESTRUCTURA EN DÍPTICO? DOS EYФHMIAI}

Se suele decir que estos discursos forman un díptico porque la ausencia de referencias a Eusebia en el Encomio a Constancio sugiere que el Encomio a Eusebia cumple la misión de alabar a la emperatriz ${ }^{33}$, y porque existiría cierta similitud en las virtudes que se ensalzan en el emperador y en su esposa ${ }^{34}$. Veamos la estructura y el contenido de las orationes:

\section{Primer Encomio a Constancio}

Exordio y propositio (1a-5a)

Encomio propiamente dicho (5b-48d)

Elogio de la patria: Roma (5b-6c)

Elogio de los antepasados: Claudio el Gótico,

Constancio Cloro, Maximiano y Constantino $(6 \mathrm{c}-8 \mathrm{~d})$

Nacimiento y educación (8d-15d)

Infancia y primera juventud. Muerte de

Constantino y ejemplar entendimiento de

Constancio con sus hermanos (15d-16c)

Elogio de las hazañas ( $\pi \rho \alpha ́ \xi \varepsilon \varepsilon 1 \varsigma)$ de Constancio $(17 \mathrm{c}-41 \mathrm{a})$

El problema persa. Preparativos para la guerra Incursión contra los persas. Constancio Reparte paz y riqueza. Batalla de Singar que puede considerarse, en vista de las circunstancias, una victoria. Descripción del tercer sitio de Nísibe (17c-30a). Sometimiento de Vetranio por medio de su persuasión. Guerra contra Magnencio. Batalla de Mursa. Elogio militar de Constancio. Nueva derrota de Magnencio, retirada a Galia y suicidio (30b$40 \mathrm{~b})$. Breve resumen de otras expediciones (40c-41a).

Elogio de las virtudes ("̌६६ıı) de Constancio (41b-49b): Piedad y humanidad con su padre, magnificencia y liberalidad con sus súbditos, templanza y prudencia, dulzura y humanidad con los enemigos derrotados.

\section{Falta Epílogo}

\section{Encomio a Eusebia}

Exordio y propositio (102a-106b)

Encomio propiamente dicho (106b-126b)

Elogio de la patria: Tesalónica (106b-107d)

Elogio de los antepasados, su padre y su madre, (107d-109a)

Alabanza del matrimonio entre Constancio II y Eusebia (109b-112a)

Elogio de las virtudes de Eusebia (112b-126a)

Enumeración de las virtudes. Al igual que Penélope, Eusebia influyó en el natural humano de Constancio, convirtiendo la justicia en clemencia. La conducta virtuosa de Eusebia queda reflejada en la ayuda que prestó a sus parientes y al propio Juliano. Consiguió que Constancio desoyera acusaciones falsas y obtuvo el permiso para su viaje de estudios a Atenas.

Excursus sobre el filohelenismo de Juliano (118c-120b)

Gratiarum actio (120b-126b): Eusebia invitó a Juliano a no rehusar el título de César. Situación de Juliano en su nueva vida. Entrevista con Eusebia, boda con Helena, el regalo de la biblioteca. Digresión sobre el valor de los libros. Renovación del agradecimiento a Eusebia.

\section{Epílogo (126b-129d)}

El sabio y divino poeta, Homero, considera esta alabanza mejor y más justa (126d-128b). Como Pericles, el mayor mérito de Eusebia es no haber causado la muerte de ningún ciudadano (128c-129b).

El recibimiento a Eusebia en Roma. Enumeración final de sus virtudes (129bd).

${ }^{33}$ Bidez, L'empereur Julien, I.1, 71; J. Fontaine, Giuliano Imperatore. Alla madre degli dei e altri discorsi, Milano 1987, xxxvii, Tougher, In praise, 109.

${ }_{34}$ Bidez, L'empereur Julien, I.1, 71-72: Constancio: valeroso, moderado, inteligente, justo, excelente, dulce y magnánimo; Eusebia: sabia, dulce, prudente, humana, equitativa, desinteresada y liberal. 
Ambos pertenecen al género del encomio y siguen pautas semejantes de organización. El exordio de uno y otro finaliza con una propositio a la que sigue el elogio propiamente dicho. Este elogio incluye una sección dedicada a la patria y a los antepasados. A partir de ahí, cada uno ofrece sus particularidades.

El Elogio de Constancio sigue a la letra los patrones escolares del $\beta \alpha \sigma \imath \lambda \iota$ iòs

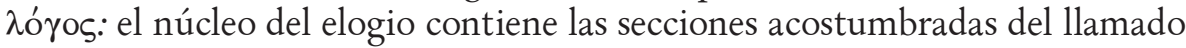
esquema biográfico: patria, antepasados, nacimiento y educación, infancia y primera juventud. El tratamiento de la madurez del emperador constituye

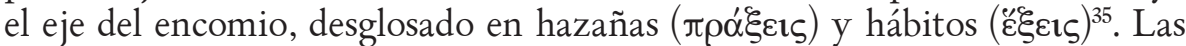
virtudes que Juliano ensalza en Constancio, su piedad y humanidad hacia Constantino, su padre, su magnificencia y liberalidad hacia sus súbditos, su templanza y prudencia, su dulzura y humanidad con los enemigos derrotados, coinciden en sustancia con las de otros encomios dirigidos al emperador ${ }^{36}$. El discurso termina con la última de las ع̌

Las propositiones señalan no sólo la organización de los discursos sino la intención del autor. En el Encomio a Constancio, Juliano indica que, como para él la virtud es lo más importante, recordará en cada una de las secciones del elogio, esto es, en su crianza, educación, en las hazañas ( $\pi \rho \alpha ́ \xi \varepsilon ı \varsigma)$ y en los

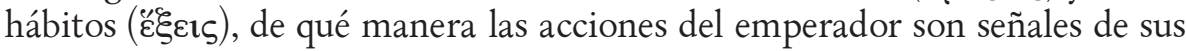
virtudes; por ello, las é ह̌દıৎ ocuparán la mayor parte del discurso ${ }^{37}$.

Los hechos desmienten las declaraciones: la narración de las $\pi \rho \alpha ́ \xi \varepsilon \varepsilon \varsigma s e$ prolonga veinticuatro parágrafos $(17 \mathrm{~b}-41 \mathrm{~b})^{38}$; mientras la sección dedicada a las

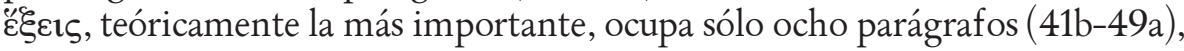
en los que repite las virtudes señaladas en el apartado anterior ${ }^{39}$. En la práctica el peso del retrato recae sobre las hazañas y no sobre las virtudes ${ }^{40}$ y estas se

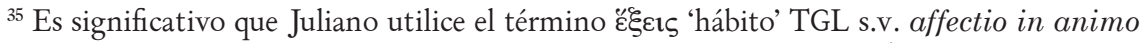
vel corpore stabilis ... sive bona sive mala, en lugar del esperado àpetaí.

${ }^{36}$ Las de la oratio 3, Sobre la realeza del propio Juliano, y las de los discursos 1-4 de Temistio.

${ }^{37}$ Jul. Or. 1.4c-5a, esp 5a: "mientras otros consideran suficiente, recordar las hazañas para

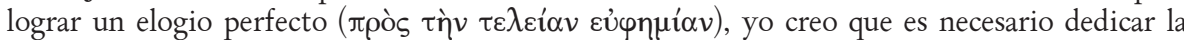

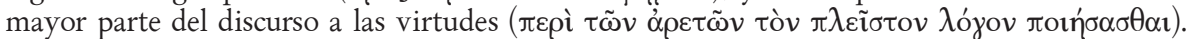
Insistirá en la misma idea al comenzar la exposición sobre las ह̌६๕ıৎ (41b).

${ }^{38}$ En los que trata las campañas contra Persia (17c-30a), el sometimiento de Vetranio (30b-33c), la guerra contra Magnencio $(33 \mathrm{c}-40 \mathrm{~b})$ y un breve resumen de otras expediciones (40c-41a).

${ }^{39}$ Piedad con su padre, justicia y moderación con sus hermanos, vida austera, valentía en el sometimiento del tirano, magnanimidad y benevolencia en la victoria.

${ }^{40}$ Ya Pernot, La Rhetorique, 152 veía en la distribución hazañas-virtudes en los dos discursos encomiásticos a Constancio un paralelismo entre el elogio retórico y el elogio filosófico en cuanto que las hazañas para Juliano son un elogio vulgar porque el resultado de las acciones depende más de la fortuna que del mérito mientras las virtudes son la materia del elogio filosófico
} 
presentan de tal manera que el discurso resulta artificial y monótono ${ }^{41}$. No es de extrañar que Angiolani lo califique como "férreo formalismo, privado de naturaleza" ${ }^{42}$.

A mi juicio, Juliano ofrece la clave de interpretación sobre su propio discurso, cuando afirma (Jul. Or. 1.23a):

Si alguien voluntariamente se aparta de ella (de la verdad) no puede escapar de ningún modo a la vergüenza de la adulación y añade a los elogios la impresión de que tampoco en otras cosas son creíbles, aun cuando sean merecidos. Tendremos cuidado en que no nos suceda esto. El propio discurso demostrará si en algo hemos honrado la mentira por delante de la verdad.

Cabe sostener, pues, que en ciertos pasajes del Encomio a Constancio Juliano se acoge a la práctica de los oradores del arte, que practican la adulación y no se avergüenzan de pronunciar un ěđaıvos falso (Jul. Or. 1.2b), porque estiman que el destinatario no es digno de uno auténtico. Mezclando elogios merecidos y adulación Juliano logra que el elogio de Constancio dé la impresión, como sostiene Athanassiadi, de "estudiada falta de originalidad"

Por su parte, el Encomio a Eusebia sigue también la pauta de los panegíricos imperiales, si bien adaptada a la condición y cualidades femeninas. Se dedica un apartado al matrimonio con Constancio. En lugar de hazañas militares, se ensalzan de distintas formas "sus muchas y bellas cualidades, los méritos que posee, su prudencia y justicia, o su dulzura y moderación, o el amor a su esposo, o su liberalidad, o su forma de honrar a sus íntimos y parientes" (Or. 2.106a). Juliano introduce una sección para dar gracias a la emperatriz por los dones recibidos. El epílogo, extremadamente amplio, comprende tres secciones diferenciadas que trataremos en el epígrafe siguiente.

Para realizar el Encomio de la emperatriz, Juliano se apoya en la autoridad de Homero ${ }^{44}$ que "no se avergonzó de elogiar a Penélope ni a la esposa de Alcínoo, ni a ninguna otra mujer que sobresaliera por su nobleza o siquiera participó de la virtud, por poco que fuera, dejó de recibir su alabanza

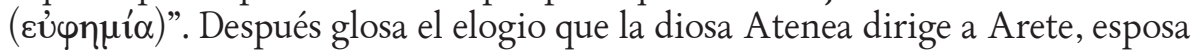

${ }^{41}$ Así, por ejemplo, el resumen de las virtudes del joven Constancio, Jul. Or. 1.16a: "Me limitaré a mostrar la superioridad de tu educación, gracias a la cual sobresaliste en belleza, fuerza, justicia y templanza, logrando una buena disposición física por medio de los trabajos, poseyendo la templanza por medio de las leyes y utilizando un cuerpo más fuerte gracias a la fortaleza de tu alma y, a su vez, un alma más justa gracias al vigor de tu cuerpo”.

${ }^{42}$ Angiolani, Elogio dell'imperatrice, 30.

${ }^{43}$ Athanassiadi, Julian, 62.

${ }^{44}$ Iul. Or. 2.104 c. Homero era una auctoritas en cualquier escrito de retórica, también la epidíctica, y, en este caso concreto proporcionaba un modelo de elogio de una esposa del monarca, Pernot, La Rhétorique, 650-652; Redondo Moyano, "Encomio", 69-70; sobre la comparación con Penélope en este mismo discurso, vid. García Ruiz, Significado de $\Sigma \omega \varphi \rho \circ \sigma u ́ v \eta, 83$. 
del rey Alcínoo, en la Odisea señalando que Arete gozó de la estima de su esposo, estaba provista de una inteligencia excelente, sabía juzgar bien y resolvía pleitos ${ }^{45}$. A continuación Juliano expone cómo será su propio discurso (Jul. Or. 2.106ab):

Imitando nosotros a aquel sabio y divino poeta [Homero], alabaremos a la excelente Eusebia y, aunque deseamos hacer un elogio digno de ella, nos contentaremos si logramos mostrar, aun en cierta medida, sus muchas y bellas cualidades, los méritos que posee, su prudencia y justicia, o su dulzura y moderación, o el amor a su esposo, o su liberalidad, o su forma de honrar a sus íntimos y parientes. Creo que conviene

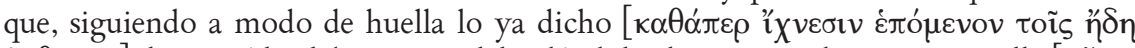

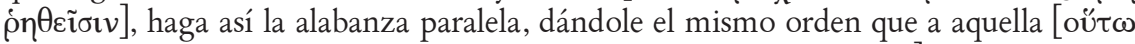

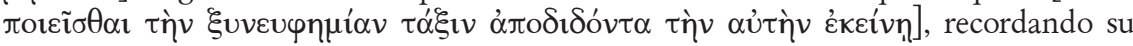
patria, como es lógico, y sus padres, y cómo se casó y con quién, y todo lo demás de la

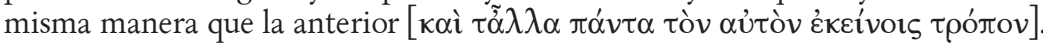

Hasta ahora se ha entendido este pasaje en referencia al anterior: Juliano imitaría a Homero tomando como pauta el elogio de la reina Arete; pero, a mi juicio, aunque haya aspectos comunes entre los encomios de Arete y Eusebia, no se puede decir que el modelo de organización ( $\tau \alpha \dot{\xi} \xi ı)$ sea el elogio de Arete. En primer lugar, porque el de Arete es excesivamente breve y carece de estructura retórica, tanto en el texto homérico como en la oratio 2; pero

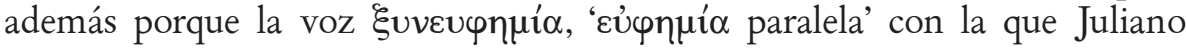

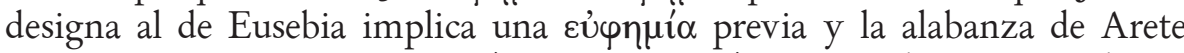

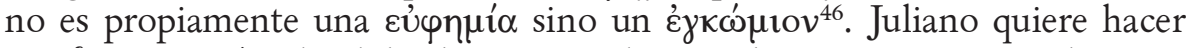
una $\xi \cup v \varepsilon v \varphi \eta \mu i \alpha$, dándole el mismo orden que la anterior. Si consideramos los discursos de Constancio y Eusebia como escritos para una misma circunstancia, podría referirse a la eủ $\varphi \eta i^{\prime} \alpha$ de Constancio, a la que nombra

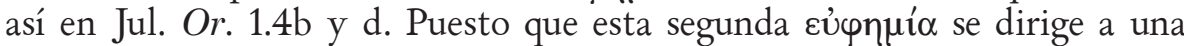
mujer, Juliano advierte que introducirá algunas variantes, "cómo se casó y con quién", y en "todo lo demás a la manera de lo dicho anteriormente" ( $\alpha$ ì

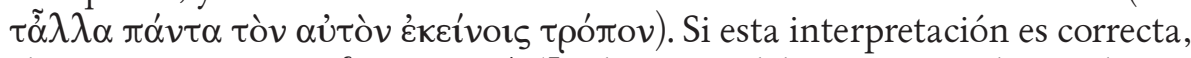

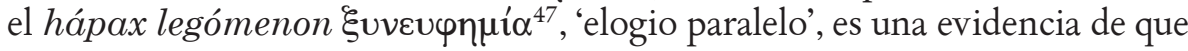

${ }^{45}$ Jul. Or. 2.104c-105d, cf. Hom. Od. 7.53-77. Ciertamente las cualidades que destaca en Arete se corresponden con las virtudes que encontramos en el Encomio a Eusebia. Como en los ejercicios escolares, Juliano adapta el original homérico a su conveniencia y elimina versos que no concuerdan con la figura de Eusebia, como: "Arete se vió honrada por él como ninguna de las mujeres de la tierra que gobiernan una casa y viven sometidas a sus esposos" (v. 68); y "ella no carece de buen entendimiento y dirime los litigios de aquellos para los cuales siente benevolencia, aunque sean hombres" (vv. 73-75).

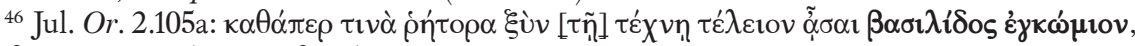

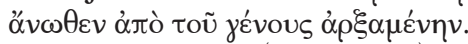

${ }^{47}$ Liddell-Scott (Supplement), s. v.: panegyric to match another, parallel laudation; cita

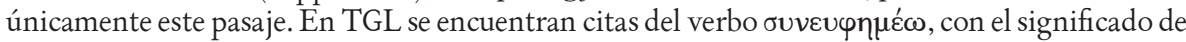
"pronunciar palabras de buen augurio", "proferir alabanzas o bendiciones", en textos anteriores 
Juliano utiliza intencionadamente el término eủ $\varphi \eta \mu i ́ \alpha$ para los dos encomios, designando así el elogio de quienes lo merecen y no lo merecen, como vimos supra. La clave de la estructura en díptico residiría no tanto en el paralelismo de las partes o en la selección de las virtudes como en la intención de llevar a

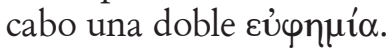

\section{LA CUESTIÓN DE LOS EPÍLOGOS}

La oratio 1 termina en un final ex abrupto con la última de las ě $\varepsilon ı \varsigma^{48}$. Ciertamente es extraño que un elogio que seguía con estricta observancia la preceptiva escolar careciera de las habituales partes celebrativas o al menos de un cierto colofón ${ }^{49}$. Bidez atribuyó la falta de expresiones de augurio en el epílogo a la premura por expedir el elogio con el chambelán Eusebio ${ }^{50}$. Este argumento no parece probable, pues es sabido que Juliano era ágil componiendo: redactó el Himno a la Madre de los dioses en menos de una noche y la invectiva Contra los cínicos incultos en dos días ${ }^{51}$. Además se aprecian otros 'descuidos' significativos: se omite la comparación del gobierno del elogiado con otro anterior ${ }^{52}$, la alabanza de la prosperidad y opulencia de que gozan las ciudades gracias a este emperador y la elevación de súplicas por su persona y descendientes ${ }^{53}$. Por el contrario, el epílogo del Encomio a Eusebia resulta un dilatado final con tres secciones independientes entre sí.

El epílogo del Encomio a Eusebia se inicia con una disculpa de Juliano: "quiero deciros unas palabras que merecen cierta atención por vuestra parte, a no ser que renunciéis por la extensión de mi discurso" 54 . La oratio había sido hasta entonces comparativamente breve $e^{55}$ pero es ahora cuando se va a prolongar de forma desacostumbrada.

o contemporáneos: Plutarco, Aetia Romana et Graega, el sofista Máximo, Dissertationes, Eusebio de Cesarea, Laus Constantini, Quinto de Esmira, Posthomerica, etc.

${ }^{48} \mathrm{El}$ discurso finaliza glosando la clemencia de Constancio hacia el hijo del usurpador Silvano, Jul. Or. 1.49": "Ni siquiera permitiste que el hijo del culpable, un niño, se viera afectado por el castigo del padre. Así tu comportamiento, inclinado a la clemencia, es indicio de tu

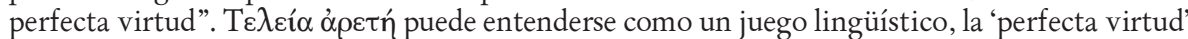
o bien como 'la última de las virtudes'.

${ }^{49}$ L. Pernot, La Rhétorique, 309-310

${ }^{50}$ Bidez, La vie, 145, 379 n.7; Bidez, L'empereur Julien, I.1, 4.

${ }^{51}$ Jul. Or. 8.178d; Or. 9, 203c; cf. Lib. Or. 18.157.

${ }^{52}$ La comparación entre la piedad de Constancio hacia su padre Constantino y la actitud opuesta de Alejandro Magno hacia Filipo (45d-46c) no cumple estrictamente esa función, puesto que refiere brevemente una una virtud y no es una comparación general como gobernante, como señalan los manuales de retórica.

${ }^{53}$ Men. Rhet. II 376, 31-377, 30.

54 Jul. Or. 2.126b.

55 El Encomio a Eusebia tiene 19 parágrafos frente a 39 parágrafos el de Constancio (exactamente los mismos que el Segundo encomio a Constancio). 
La primera de las secciones del epílogo (126d-128b) es una larga disertación sobre por qué Homero eligió honrar las virtudes conyugales de Penélope, en lugar de cantar las hazañas de mujeres como Semíramis, Nitocris, Rodoguna o Tomiris $^{56}$. Con ella ilustra la disyuntiva entre ensalzar las grandes hazañas del gusto de todos o realizar el elogio de las virtudes en apariencia insignificantes. La reflexión finaliza así (Jul. Or. 2.128b):

... de la virtud y moderación de aquella [Penélope] se siguen muchos bienes para los hombres, tanto en la vida privada como en la pública, mientras que de la ambición de

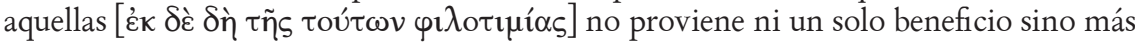
bien desgracias irremediables. Por eso es por lo que creo que el sabio y divino poeta

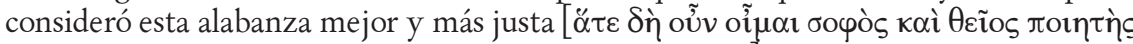

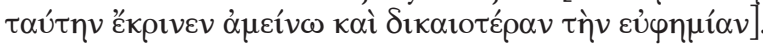

En ningún pasaje de la Odisea se dice que gracias Penélope se siguieran muchos bienes para los hombres, ni las heroínas aquí nombradas destacaron precisamente por su ambición ${ }^{57}$; pero, teniendo en cuenta que el trasvase de atributos de Eusebia a Penélope es un recurso asiduo en la oratio $2^{58}$, el pasaje cobra sentido si en lugar de Penélope vemos a Eusebia. La emperatriz sí había desplegado benevolencia hacia parientes, ciudadanos privados y públicos entre los que se encontraba el propio Juliano, a diferencia de quienes erraron en el uso de las riquezas ${ }^{59}$.

Pero este no es el único de los personajes figurados. Tras 'el sabio y divino poeta' se encuentra Juliano. En primer lugar, porque la expresión 'el sabio y divino poeta' funciona como un eco de la propositio donde Juliano anunciaba que iba a alabar a Eusebia, imitando a Homero: "imitando nosotros al sabio y divino poeta alabaremos a la excelente Eusebia" ${ }^{60}$. Juliano ha cantado las pequeñas virtudes de Eusebia prefiriendo estas a las grandes hazañas de las

${ }^{56}$ Semíramis, reina de Babilonia, levantó maravillosos palacios bajo tierra y una gran muralla y otras lujosas y costosas construcciones, y realizó otras grandes hazañas (Jul. Or. 2.127a; Diod.Sic. 2.4-21; cf. Jul. Or. 3.83c; 92a donde Juliano critica que grandes obras como esas no hacen un gran rey, porque no le dan la virtud). Nitocris, fue la reina que vino después de esta y realizó diversas obras de ingeniería en el Eufrates (Herod. 1.185-187). De Rodoguna, hija de Jerjes (Ctes. Pers. 20, apud. Phot. p.118) o de Artajerjes (Plut. Art. 27.8); o según otros, hija del rey de los partos Mitrídates I y esposa del rey seleúcida Demetrio II Nicanor, sabemos que hizo voto de no lavarse ni cepillarse el pelo hasta que se acabara con una revuelta (Pol. 8.27; cf. Philos. Im. 2.5.217). Tomiris, reina de los maságetas, se enfrentó con su ejército a Ciro, rey de Persia, para vengar la muerte de su hijo Espargapises (Herod. 1.211-214).

${ }^{57}$ Vid. nota 55 .

${ }^{58}$ Sobre la inversión de atributos entre Penélope y Eusebia, García Ruiz, Significado de

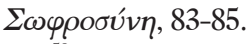

${ }^{59}$ En esta misma línea Jul. Or. 2.121d-122a: "para los que yerran en el uso de las riquezas (estas) son perjudiciales y causa de innumerables desgracias para las familias y para muchas ciudades".

${ }^{60}$ Jul. Or.2.106a. 
heroínas. Y en segundo término porque me atrevería a decir que, revestido de ropaje homérico y sirviéndose de esta pseudo-parábola, Juliano da su

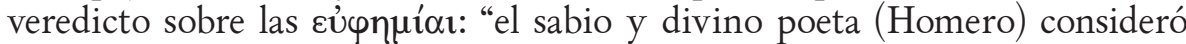

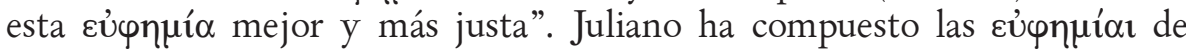
Constancio y Eusebia. La de Eusebia fundada en la alabanza de las virtudes, la de Constancio en las hazañas como las de las grandes heroínas de la Antigüedad. Considera que la de Penélope-Eusebia es mejor y más justa: 'más justa' probablemente en términos filosófico-morales, porque se asienta en las virtudes, y 'mejor' porque sería de mayor calidad oratoria que la de Constancio. Juzgar las eủ actuales' como había prometido al comenzar la sección ${ }^{61}$, sólo que dichas de tal modo que pasaran desapercibidas ${ }^{62}$.

En la segunda de las secciones del epílogo, el orador establece un símil entre Eusebia y el famoso gobernante y orador Pericles (128c-129b). Cumple, sin duda, la recomendación de Menandro de parangonar al elogiado con personajes célebres para así resaltar la perfección del presente (Men. Rhet. $2.376,31-377,9)$. A lo largo del elogio el panegirista ha insistido en que ella se había hecho digna de participar en las deliberaciones de su esposo y que influía en sus decisiones ${ }^{63}$, pero aquí la sitúa en una posición superior. Lo extraordinario no es sólo que compare a Eusebia nada menos que con Pericles, sino que Constancio no haya recibido un tratamiento equivalente.

Pericles se enorgullecía de no haber sido culpable de la muerte de ningún ciudadano ${ }^{64}$, pero Eusebia "es digna de todos los elogios porque no ha dado muerte a ningún ciudadano, ni le ha arrebatado sus bienes, ni le ha arrojado a un injusto exilio" (128d). Esos son precisamente los cargos de los que Juliano acusaba a Constancio años después, en el 361, en la Epistola a los atenienses (Jul. Or. 5.270cd, 271bc, 273ab) ${ }^{65}$ :

Ese clementísimo emperador, iqué cosas nos ha hecho!: a seis primos míos, que también lo eran suyos, a mi padre, que era su tío, y, además, a otro tío común por parte de padre y a mi hermano mayor, los hizo matar sin juicio, y a mí y a mi otro hermano, aunque quiso matarnos, finalmente nos envió al exilio... encerrados en un campo de Capadocia, sin que permitiesen que nadie se nos acercara... [Yo] nada tenía de la hacienda paterna ni poseía nada de todo lo que, presumiblemente, mi padre había poseído, ni el más pequeño trozo de tierra, ni un esclavo ni una casa. Porque el bueno de Constancio habia heredado, en mi lugar, todos los bienes paternos y a mi, como he dicho, no me dio absolutamente nada.

\footnotetext{
${ }^{61}$ Jul. Or. 2.126b.

${ }^{62}$ Sobre la crítica implícita hacia Constancio en los discursos vid. infra.

${ }^{63}$ Jul. Or. 2.114a-115d.

${ }^{64}$ Es probable que Juliano se inspirase en Plutarch. Pericl. 38.

${ }^{65}$ Tougher, In praise, 120.
} 
Es decir que, mientras Juliano exaltaba el comportamiento virtuoso de Eusebia, estaba poniendo en evidencia, aunque fuera sutilmente, la conducta reprobable de Constancio. El símil finaliza destacando que lo principal del elogio a Eusebia es que la emperatriz utiliza su carácter y autoridad para hacer el bien a todos (Jul. Or. 2.129b). Juliano atribuye a Eusebia carácter y autoridad, rasgos de un buen gobernante que no se encuentran en el elogio de Constancio. Toda esta sección resultaría un durísimo reproche encubierto hacia Constancio sobre el que volveremos en el apartado siguiente.

En la tercera parte del epílogo (129b-d), se narra el viaje que la emperatriz realizó a Roma un año antes, "mientras Constancio marchaba en campaña atravesando el Rin con su puente de barcas cerca de la frontera de la Galia"66. Juliano renuncia a exponer con detalle los pormenores de la visita: "hubiera podido recordar con qué alegría el pueblo y el senado la recibieron (a Eusebia)... la grandeza de los gastos, lo costoso de los preparativos y cuánto distribuyó a los presidentes de las tribus y a los centuriones del pueblo". Son los tópicos habituales de la descripción de un adventus imperial, pero no así su enfoque: Juliano no quiere alabar la riqueza por delante de la virtud, un pensamiento que se repite en otros lugares del Encomio ${ }^{67}$, coherente con el elogio de las virtudes.

Según Tantillo y Angiolani, esta evocación del viaje de la emperatriz a Roma junto a otros comentarios dispersos por las orationes 1 y 2 son indicios del acontecimiento para el que ambas fueron escritas ${ }^{68}$, otro de los interrogantes que la crítica se afana por resolver. Para estos autores Juliano habría preparado los discursos con intención de sumarse a las ceremonias que iban a tener lugar en Roma en la primavera del $357^{69}$. En ellas se celebraba el triunfo sobre Magnencio ${ }^{70}$, las victorias contra los alamanes y los vicennalia de Constancio ${ }^{71}$. Refrendaría esta tesis la consideración de Roma como 'patria' del emperador, cuando este había nacido en Iliria (Jul. Or. 1.6ac); y el breve excursus sobre el consulado, al realizar el elogio del padre de la emperatriz que había desempeñado esta magistratura como homo novus (Or. 2.107d-109a). Estos enfoques eran apropiados para la celebración ya que centraban la atención en la capital del Imperio y en el consulado de Juliano y Constancio. El énfasis en que la guerra con Magnencio había sido un atropello

${ }^{66}$ Jul. Or. 2.129b.

${ }^{67}$ Jul. Or. 2.129cd, cf. Jul. Or. 2.121d-122a y 128b.

${ }_{68}$ Tantillo, Prima orazione, 39-40; Angiolani, Elogio dellimperatrice, 22-29.

${ }^{69}$ En ese contexto las desavenencias con Marcelo le habría hecho enviarlos con Euterio para manifestar así su adhesión al emperador.

70 Único motivo citado por Amm. Marc. 16.10.

${ }^{71}$ Angiolani, Elogio dell’imperatrice, 22-23 n. 80. Sobre la cronología de los vicennalia, Constancio cuenta como fecha de inicio de su reinado el fallecimiento de Constantino en Mayo del 337, O. Seeck, "Constantius”, RE IV , 1, 4, 1900, col. 1081. 
contra el Estado y contra la familia de Constancio (Jul. Or. 1.42a, cf. 34a-d y Or. 2.109a) también encaja en ese contexto ${ }^{72}$.

No resulta desatinado pensar que el emperador le hubiera encargado los discursos a Juliano teniendo en cuenta sus habilidades retóricas y que en ese año 357 compartía por segunda vez el consulado con Constancio. La presencia de la emperatriz en Roma refuerza la conveniencia de dedicarle a ella una sección significativa en las ceremonias.

$\mathrm{Si}$, como parece, los Encomios tenían como marco las celebraciones de la primavera del 357 en Roma, una alusión a la ya cercana visita del emperador y su esposa a Roma hubiera sido muy apropiada como colofón ${ }^{73}$. El recuerdo del viaje realizado anteriormente por Eusebia en solitario parece un vestigio de un tratamiento más amplio centrado en el inminente adventus de Constancio en la Urbe.

El discurso a Eusebia concluye con una última enumeración de las virtudes de Eusebia (justicia, moderación y prudencia) ${ }^{74}$, en coherencia con lo que ha sido, un elogio construido sobre virtudes.

El análisis de este largo epílogo ha puesto en evidencia conexiones entre ambos discurso pero también ha suscitado nuevos interrogantes. La sorprendente presencia de críticas directas o indirectas hacia la persona del emperador, el excesivo protagonismo de la emperatriz a la que se atribuyen las cualidades del buen gobernante y la falta de referencias expresas a lo que parece ser el motivo que llevó a Juliano a escribir los discursos: la celebración del triunfo de Constancio sobre Magnencio y sus vicennalia.

\section{PASAJES SORPRENDENTES Y ARRIESGADOS}

Estudiamos la primera de las cuestiones que ha aflorado como elemento distorsionante, las críticas a la figura de Constancio.

Desde siempre la presencia de comentarios mordaces contra el emperador en un discurso temprano, como es el Encomio a Constancio, ha causado extrañeza entre los estudiosos. Como ha señalado recientemente Tougher ${ }^{75}$, resulta insólito que, en un texto encomiástico dirigido al emperador, Juliano mencione asuntos familiares sensibles como la masacre del 337 en la que murieron varios miembros de su familia, sus padres y varios hermanos, justificando la actitud del emperador: "no pudiste impedir que otros obraran contra tu voluntad" (Jul. Or. 1.16d-17a); cuando años más tarde le acusaría abiertamente de haber sido el instigador principal (Jul. Or. 5.270cd).

${ }^{72}$ Alejaba así la interpretación del enfrentamiento como una guerra civil, en ese caso Constancio no hubiera tenido derecho al triunfo, como recuerda Amm. 16.10.1.

${ }^{73}$ Véase ese tipo de referencias en otros discursos contemporáneos como Temistio, Or. 3 , Discurso de embajada en Roma pronunciado en nombre de Constantinopla (357), o Lib. Or. 13, Discurso de bienvenida (a Antioquía) a Juliano (362).

${ }^{74}$ Jul. Or. 2.129d.

75 Tougher, Reading, 27-28. 
Igualmente es llamativo que califique de ejemplar el entendimiento entre los hijos de Constantino (Jul. Or. 1.15d-16c, 18c). Todos estos comentarios parecen sobrepasar los límites de la adulación acostumbrada en un elogio para adentrarse en el terreno de una peligrosa ironía.

A esos pasajes ha de sumarse la acusación encubierta que acabamos de señalar en el Encomio de Eusebia: Constancio no sería digno de elogio por haber dado muerte a ciudadanos, haberles arrebatado sus bienes o arrojarse al exilio (Or. 2.128d), acusaciones que esgrimiría contra él años más tarde. Hay otras críticas indirectas que también parecen tener como destinatario al emperador: a los que yerran en el uso de las riquezas (Or. 2.121d-122a; 129a), y a quienes con su ambición causan desgracias irreparables (Or. 2.128b).

Los textosfaltos de tacto político del Encomio a Constancio han producido desconcierto entre los críticos: algunos los han interpretado como sarcasmos revestidos de adulación ${ }^{76}$, Tantillo como licencias propias de un 'filósofo' que deseaba crear su propio estilo retórico ${ }^{77}$. Tougher considera que podrían ser entendidos de diferentes maneras por distintas audiencias ${ }^{78}$. Pero, a mi juicio, esas críticas mordaces más o menos soterradas difícilmente hubieran podido ser pronunciadas ante cualquier auditorio sin causar problemas a un joven César, sometido al emperador. Por aquel entonces Juliano necesitaba ganarse la confianza de Constancio, no provocar su ira, y los hechos muestran, como hemos recordado, que las relaciones entre el emperador y su César mejoraron precisamente a partir de aquellos primeros meses del 357.

La teoría de la rescritura, sugerida ya por Geffcken y Raeder para la oratio 1 y por Angiolani y por James para la oratio 2, permitiría explicar la presencia de esas críticas contra Constancio en ambos encomios, aduciendo que son parte de la revisión ${ }^{79}$. Con ellas Juliano pretendería mostrar una imagen del emperador -suspicaz, ambicioso y cruel- que concordara con sus acusaciones ulteriores.

\section{CONSIDERACIONES FINALES}

Los Encomios dirigidos al emperador y a la emperatriz son discursos ensamblados como ya apuntaban autores recientes. En este trabajo hemos señalado huellas de esa conexión. Una de ellas la encontramos en la disyuntiva entre elogio filosófico y elogio retórico, que Juliano resuelve elaborando una

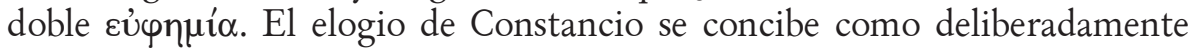

${ }^{76}$ E. Talbot, L'empereur Julien. Oeuvres complètes, Paris 1863, xxxii y R. D’Alfonso, I retori nel secolo IV, Imola, 1900, 57-61, cit. en Tantillo, Prima orazione, 13; Fontaine, Alla madre, xxxvii quien denomina a ese conjunto de alabanzas 'antífrasis sarcásticas'.

77 Tantillo, Prima orazione, 16.

78 Tougher, Reading, 29.

${ }^{79}$ Propuesta ya por J. Geffcken, Kaiser Julianus, Leipzig 1914 y A. Raeder, Julian den Frafaldne, Olso 1932 y por Angiolani, Elogio dellimperatrice, y James, Is there an empress, 47-59 para la oratio 2. 
escolar y artificial, porque Juliano se acoge a la práctica de los rétores y

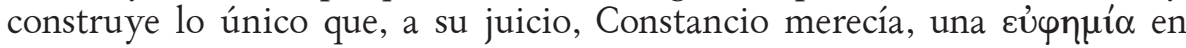
términos neutros, un ع̈ đalvos falso en los términos del elogio filosófico. En cambio, el de Eusebia pretende ser un ě̃ $\alpha \imath v o \varsigma$ verdadero: Juliano afirma que las obras de Eusebia eran testimonio de sus virtudes ${ }^{80}$, se ofrece a sí mismo como testigo y niega que en su discurso hubiera nada falso ni inventado ${ }^{81}$.

La técnica es la misma que utilizó en el Segundo encomio a Constancio, un elogio retórico seguido de un elogio filosófico. En Sobre la realeza se avergüenza del elogio retórico porque este se aparta de la virtud, y sólo considera auténtico elogio el elogio filosófico ${ }^{82}$. La novedad es que esa dualidad está presente en el planteamiento de las orationes 1 y 2 . Si aplicamos sus principios sobre la práctica del elogio, Juliano pretendía agradar a la pareja imperial con sus panegíricos, estimulando a la virtud al emperador y predisponiendo a la emperatriz a otras acciones hermosas y superiores (cf. Jul. Or. 2.103c). ¿Era esa la finalidad original de las orationes o este juego retórico es fruto también de la revisión?

En cuanto a la estructura original de los discursos, ¿eran un único discurso o dos discursos escritos para una misma circunstancia? Existen indicios en ambas orationes de que fueron pronunciados o redactados para las ceremonias con motivo del triunfo de Constancio y de sus vicennalia; sin embargo, en el estado actual de los textos no hay huellas de una estructura compartida al estilo del Elogio de los emperadores Constancio y Constante de Libanio (Or. 49) o rastro de que el discurso de la emperatriz fuera parte del del emperador, tal y como proponía Menandro (Men. Rh. 2.376.9-13).

Por otra parte, la ausencia del epílogo en el Encomio de Constancio y la prolongada duración del de Eusebia con sus críticas soterradas a Constancio y la evocación del viaje en solitario de Eusebia a la Urbe, son elementos que refuerzan la tesis de que estamos ante versiones revisadas: a nivel estructural, Juliano habría eliminado partes celebrativas (esenciales en un discurso epidíctico) dirigidas a Constancio, como la comparación con un gobernante de la Antigüedad, la referencia al ya inminente adventus en Roma y los augurios finales.

${ }^{80}$ Jul. Or. 2.106a, 112d, 114b, 115a, 116c, 117a, 128d-129a.

${ }^{81}$ Jul. Or. 2.116d: "puesto que veo que mi discurso necesita de pruebas lo mismo que si estuviera en un tribunal, yo mismo me ofreceré a vosotros como testigo y panegirista de aquellas acciones; pero para en ningún caso sospechando de mi testimonio, os alborotéis antes de escuchar mis palabras, os juro que no diré nada falso ni inventado".

${ }^{82}$ Jul. Or. 3.79cd: "un no pequeño temor me asalta acerca de mis anteriores palabras y de mí mismo, no vaya a ser que mostréis que aquellas eran puerilidades y yo mismo un sofista ridículo e ignorante al aplicarme a un arte en el que confieso ser muy inexperto, de manera que debo confesaros que voy a presentar los elogios auténticos que vosotros juzgáis dignos de escuchar, aunque a la mayoría pueden parecerle demasiado rústicos y muy inferiores a los ya dichos". 
Juliano llevó a cabo esta revisión o reescritura en las orationes 1 y 2 en momentos en que se sentía fuerte frente al emperador. Parece probable que Juliano, una vez se hubo proclamado Augusto, en fecha que futuros trabajos habrán de determinar ${ }^{83}$, quisiera suprimir las partes de la versión original que caracterizaban de forma favorable al emperador. Juliano pretendería mostrar una imagen del emperador que supusiera una continuidad con la ofrecida en escritos ulteriores ${ }^{84}$ y quizá también pretendería suprimir evidencias de una actitud de mayor sometimiento a Constancio por su parte.

En este estudio se han puesto de relieve dos cuestiones de no poca importancia en relación con estos discursos: que al igual que en el Sobre la realeza Juliano combina elogio retórico y elogio filosófico en un agudo juego retórico, y que nos encontramos ante versiones revisadas de los textos probablemente con vistas a establecer una coherencia en su representación del emperador Constancio y en la idea de proteger su propia imagen ante la posteridad.

${ }^{83}$ I. Labriola, I due autoritratti di Giuliano imperatore, Belfagor 29, 1974, 546-560, argumentó de forma convincente un proceso similar respecto de la Epistola a los atenienses. Según la autora, la carta fue retocada para su publicación, cuando Juliano escribía el opúsculo Misopogon hacia marzo del 363.

${ }^{84}$ M. Humphries, “The tyrant mask? Images of good and bad rule in Julian's Letter to the Athenians", en N. Baker-Brian and S. Tougher (eds.), Emperor and author. The writings of Julian the Apostate, Swansea 2012, 83-87; N. Baker-Brian, “The politics of virtue in Julian's Misopogon", en N. Baker-Brian and S. Tougher (eds.), Emperor and author. The writings of Julian the Apostate, Swansea 2012, 268-277 anuncian futuros trabajos sobre la imagen de Constancio en esta dirección. 
